\title{
Modelos de ficción de performance original en la literatura helenística: una primera aproximación
}

Alejandro Abritta

Universidad de Buenos Aires / CONICET, Argentina alejandroabritta@gmail.com

\author{
Pablo Martín Llanos \\ Universidad Nacional de Córdoba / CONICET, Argentina \\ pablomartinllanos@gmail.com
}

\section{Resumen}

En el presente artículo se introduce el concepto de ficción de performance original para el análisis de la literatura helenística a partir de algunas consideraciones generales sobre los cambios culturales en el período y luego a través de un recorrido de sus aplicaciones a algunos de los poetas más reconocidos. Se pretende demostrar que el marco teórico inaugurado en Llanos (2017) resuelve algunas de las dificultades más persistentes en el estudio de la poesía helenística y además produce una visión más unificada de las diferentes técnicas compositivas en ella que los esquemas disponibles actualmente.

\section{Models of fiction of original performance in Hellenistic literature: a first approximation}

\begin{abstract}
In this paper we present the concept of fiction of original performance for the analysis of the Hellenistic literature, starting with some general observations regarding the cultural changes in the period and then studying its applications to some of the most important poets. We pretend to prove that the theoretical framework stablished in Llanos (2017) solves some of the most persistent difficulties in the study of Hellenistic poetry and also produces a more unified vision of the different compositional techniques in it than the currently available systems.
\end{abstract}

\section{Palabras clave}

Ficción de performance original epigrama Apolonio calímaco Teócrito

\section{Keywords}

Fiction of original performance epigram Apollonius Callimachus Theocritus 
1. Sobre el concepto de 'contexto de performance' que se utilizará aquí, cfr. la secc. 2.

2. Cfr. Ford (1988:303). Por 'no cantada' no debe entenderse 'sin melodía', sino 'sin una melodía especialmente desarrollada para el texto.' No entraremos aquí en el problema de la melodía de la poesía en la época arcaica, sobre el cual cfr. Comotti (1989). En ocasiones, un rapsoda podía acompañarse con la cítara o incluso con el aulós. Nótese, por cítara o incluso con el aulós. Nótese, por
lo demás, que no todos los elementos del contexto de performance están en el mismo nivel de importancia en cada caso (a veces, por ejemplo, la ocasión de ejecución es fundamental, a veces es intrascendente): la jerarquía de rasgos es un aspecto tan definitorio como los rasgos mismos (cfr. secc. 2).

3. La idea de una 'reconstrucción' está bien establecida para la época helenística; cfr. Rossi (1971), un locus, si algo anticuado, clásico sobre el tema. Cfr. también Fantuzzi; Hunter (2007:22-26); nótese que esto no implica que la lectude los textos. De hecho, debemos señalar desde ya que no pretendemos negar que hubiera en el periodo performances poéticas efectivas ni que todas las prácticas de performance de la época clásica desaparecieran a partir del s. IV a.C.; sin embargo, para el grueso de la poesía que conservamos, sus contextos posibles de performance (por ejemplo, la corte ptolemaica) no responden a las convenciones de las épocas arcaica y clásicay, además, los modos de circulación de la poesía se han modificado radicalmente.

4. Sobre el concepto de 'memoria esquemática' y su importancia en el análisis de la música, cfr. Huron (2006:203-238).

5. El ejemplo, por obvias razones, simplifica la complejidad del panorama musical contemporáneo, pero entendemos que es lo suficientemente ilustrativo como para justificar la simplificación.

\section{Introducción}

En los últimos años, la idea de que el contexto de performance de un texto era un elemento definitorio en la elaboración y recepción de la poesía griega se ha convertido en un principio disciplinar (cfr., por ejemplo, Rotstein, 2010). ${ }^{1}$ La 'rapsodia', por ejemplo, se definía en la época arcaica y clásica como un tipo de performance, solitaria, no cantada y, en general, sin acompañamiento musical. ${ }^{2}$ Aunque los esquemas se complejizan progresivamente y los límites siempre resultan difusos, durante estos períodos la recepción de la poesía incluía necesariamente una cierta concepción del ámbito y modo para el que fue compuesta, en general por la sencilla razón de que era recibida en ese ámbito y de ese modo.

Que este estado de cosas se modifica en la época helenística es un hecho extremadamente conocido y reconocido. En la Alejandría ptolemaica, pero también en general en el mundo helenizado, los poemas clásicos eran leídos y los espacios de recepción para los que fueron compuestos debían ser reconstruidos por los lectores. ${ }^{3}$ En paralelo a esto, la poesía compuesta por los autores de la época parece tener una relación compleja con su contexto, lo que ha dado lugar a numerosos debates sobre la cuestión de su performance con vericuetos específicos para cada poeta.

Nuestra intención en este trabajo es presentar un concepto que ofrece la posibilidad de abarcar una parte considerable del problema del contexto de performance en la época helenística y ofrecer una postura unificada que comprende situaciones tan disímiles como las de Teócrito y Herondas, Apolonio y el epigrama literario, Calímaco y Licofrón. Nos referimos a la noción de 'ficción de performance original', presentada por primera vez por Llanos (2017). Antes de introducir esta noción, sin embargo, puede resultar útil detenerse en la delimitación del concepto de 'contexto de performance'.

\section{Definición instrumental de contexto de performance}

A lo largo de este trabajo, utilizaremos 'contexto de performance' para referirnos en sentido amplio a una serie de aspectos de la ejecución poética que la caracterizan: ocasión, tipo de ejecución (solitaria, coral; cantada, recitada), acompañamiento, carácter ritual, relación entre el ejecutor y su audiencia y entre el poeta y el ejecutor, trasfondo sociopolítico y algunos etcéteras. que deben definirse en cada caso.

En cierto sentido, en la aproximación a la poesía griega que ofrecemos aquí, el contexto de performance es el equivalente del lado de la emisión de lo que en el receptor son los rasgos que activan la memoria esquemática que permiten reconocer un género poético o musical específico. ${ }^{4}$ La situación en la antigüedad pre-helenística en muchos aspectos habría sido comparable con la forma en que hoy en día se experimenta la música (en vivo): si una persona entra a un teatro como el Teatro Colón en la Ciudad de Buenos Aires, se acomoda y observa en el escenario un grupo de personas vestidas de traje y sentadas, con violines, chelos, clarinetes, etc., sabe qué tipo de música puede esperar escuchar y sabe que es completamente diferente de lo que podría escuchar si entrara a un estadio de fútbol y se encontrara frente un escenario montado con dos guitarras eléctricas, un bajo y una batería. ${ }^{5}$ 
En forma similar, un oyente antiguo que se sentara en un teatro y viera entrar cantando un coro acompañado por un aulós sabe que no puede esperar lo mismo que si viera entrar un solo intérprete cargando una lira. En diferentes ámbitos, por lo demás, distintos factores resultan determinantes. Así, por ejemplo, mientras que en los dos ejemplos contemporáneos dados arriba los instrumentos, el ambiente y la ropa resultan esenciales, si uno viera a una persona sin una vestimenta particular, en el pasillo de una estación de tren subterráneo y preparándose para tocar una guitarra criolla, para recortar las expectativas respecto a lo que va a ejecutar debe esperar a escuchar la música. ${ }^{6}$ En la Antigüedad pre-helenística, aunque la convencionalización habría sido mayor, funciona de manera idéntica: en un teatro durante las Dionisíacas, el mencionado coro acompañado del aulós daría un indicio inequívoco de que se va a escuchar un canto lírico de una tragedia, pero un rapsoda que entra en un escenario puede estar a punto de recitar una elegía, un yambo de Arquíloco, un himno, etc. ${ }^{7}$

Los elementos que delimitan las expectativas respecto de lo que la pieza poético-musical en cuestión puede incluir no son, por supuesto, una mera abstracción en el cerebro de los receptores, sino que funcionan también como convenciones que los autores reconocen y utilizan. No se puede componer (en el siglo V a.C. y por lo menos hasta donde sabemos) una tragedia sin coro, pero es posible componer una pieza poética que pueda ser acompañada por el aulós, por la lira o por nada. En un caso, el contexto de performance del género restringe ciertas posibilidades para el poeta pero le ofrece otras (por ejemplo, la posibilidad de contar con múltiples voces); en el otro, el contexto deja mucho a la elección del intérprete. Lo que es importante notar en ambos casos es que en los dos el contexto es un dado: ni al componer una tragedia ni al componer una elegía el poeta elije el contexto pretendido del género, que es un esquema cultural fijo reconocible por los receptores. ${ }^{8}$ Es precisamente la caída, la multiplicación o difuminación de estos esquemas lo que lleva al estado de situación de la época helenística.

\section{El concepto de 'ficción de performance original'}

Por 'ficción de performance original' no nos referimos a una 'imitación' de una ejecución real, como las que se han propuesto para los himnos 'miméticos' de Calímaco. No sostenemos que los poetas 'imitaban', en particular porque queremos evitar la oposición entre una composición 'imitativa' y una 'no imitativa'. Tampoco debe confundirse 'ficción de performance original' con un concepto más amplio de 'ficción de performance', en el que un poema que quizás no fue jamás ejecutado se compone como si estuviera hecho para ser ejecutado. ${ }^{9}$ El concepto que queremos introducir se subsume en cierta medida bajo este, pero con características especiales.

La ficción de performance original (a partir de este punto, FPO) es una técnica literaria que define la identidad genérica de un poema. No siendo ya el contexto efectivo de performance el que permite esa definición, es la construcción de un contexto de performance a través de las palabras del texto la que lo hace. En la FPO, un autor incorpora en sus poemas marcadores que sugieren una ocasión o tipo de ocasión determinado y un tipo y modo de ejecución determinado; el texto que el lector lee es, dentro del pacto ficcional, una transposición de esa forma original al medio escrito o la ejecución que se escucha funciona como re-performance de un texto cuyo contexto de performance original
6. Esto no significa que el contexto no influya en las expectativas (es obvio que en esta situación no se puede esperar lo mismo que en las otras dos descriptas), sólo que los elementos determinantes son acústicos.

7. Cfr. sobre la amplitud del concepto de rapsodia Ford (1988). Nótese que, visto así, la 'rapsodia' es un género de la misma manera que el 'rock' es un género: aunque posee una unidad, presenta variedades muy distintas entre sí.

8. Un compositor acaso podría componer una 'elegía para lira' que luego sería ejecutada sin acompañamiento musical por un intérprete. Esto no va en detrimento del punto, porque la delimitación 'para lira' no es propia del género, sino de la obra en particular.

9. Una 'ficción de performance' de este tipo podría quizás aplicarse a textos hexamétricos de la época imperial, como los de Opiano o Nono, cuya técnica recupera formas de composición propias de modos poéticos performativos para textos cuya transmisión es exclusivamente por escrito. 
10. A los fines de este trabajo, nos limitaremos al receptor helenístico culto (no necesariamente erudito).
11. Lo hacemos a partir de la edición de Gow; Page (1965). Las traducciones son nuestras. es otro. El receptor ${ }^{10}$ es consciente de la ficción; la clave del concepto es precisamente el acuerdo tácito a través del cual el autor y el receptor pretenden que una cierta performance fue el origen (y el estado original) del texto. El receptor es pensado por el escritor, en este sentido, como alguien capaz de rastrear en el texto las huellas de ese 'estado original'.

Resulta evidente el proceso de desarrollo de esta técnica compositiva. El filólogo alejandrino y acaso el lector culto helenístico en general suponen en su lectura de, por ejemplo, los poemas homéricos que existe un estado original de esos poemas, a saber, la ejecución rapsódica. Sobre esta base y junto con la consciencia de la importancia del contexto de performance para la determinación genérica de un texto, en la elaboración de la nueva poesía los autores incorporan los marcadores necesarios para la reconstrucción del contexto de maneras más o menos sofisticadas.

Consideramos prototípico de este proceso el desarrollo del epigrama literario en la época helenística. Mientras que el epigrama inscripto no necesita presentar información sobre el contexto en el que está inscripto, puesto que el lector ineluctablemente está frente a ese contexto, su sucesor helenístico no puede presuponer que el receptor sabe de qué se está hablando. En otras palabras, mientras que un epigrama debajo de una estatua no tiene necesidad de describir la estatua o siquiera de señalarse a sí mismo como epigrama dedicatorio de una estatua particular, cuando un epigramatista escribe un poema que pretende ser el acompañamiento a una escultura determinada, es imprescindible indicarle al lector ese hecho de alguna manera.

Las técnicas a las que se apela son múltiples y abarcan el uso de convenciones epigráficas (como la aparición de nombres en acusativo o genitivo) (Bettenworth, 2007), el metro y la alusión específica a un tipo de inscripción, que varía desde la simple mención del objeto sobre el que supuestamente el

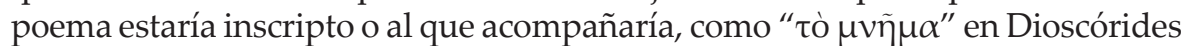
26 G.-P. [= A.P. 7.450]) o Leónidas 12 G.-P. [=A.P. 7.448], que citamos: ${ }^{11}$

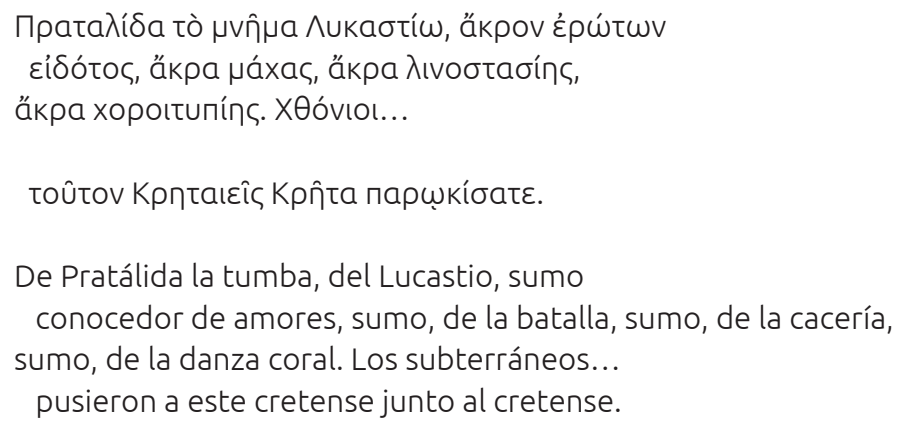

hasta la construcción de un acertijo a partir de la descripción de las características de un monumento y su interpretación subsecuente, como en Posidipo 19 G.-P. [= A.P. 16.275] o Antípatro 29 G.-P. [= A.P. 7.424]:

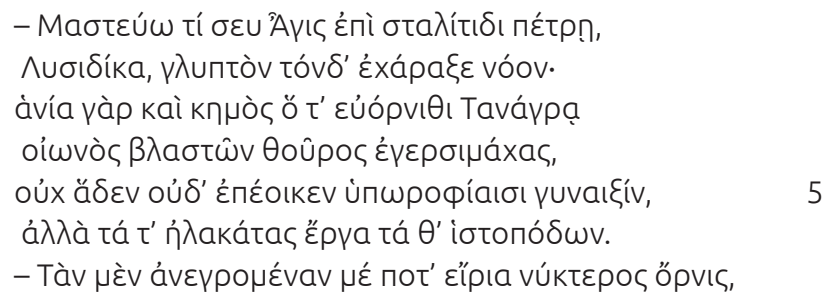




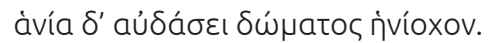

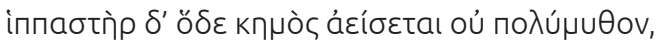

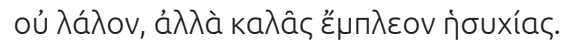

- Me pregunto por qué Agis sobre tu piedra inscripta,

Licídice, cinceló este signo grabado;

pues brida y bozal y en Tanagra de buenas aves

nacido el pájaro, impetuoso, listo para la batalla,

no place ni conviene a una mujer de vida hogareña,

sino los trabajos del telar y la rueca.

- Que yo toda la noche la lana alguna vez movía el pájaro

cantará y la brida que fui auriga de mi casa.

El equino bozal cantará que no fui charlatana, ni habladora, sino llena de bello silencio.

El punto a destacar no es que estos poemas 'imitan' o 'fingen' tener un contexto, sino que, primero, se esfuerzan por definirse a sí mismos a través de la reconstrucción de su contexto (para ser un epigrama consagratorio se debe estar en un objeto consagrado) y, segundo, los marcadores usados para lograr esto se utilizan a su vez como recursos literarios para generar efectos complejos. Cuando el epigramatista elabora un acertijo a partir de los rasgos de una escultura no sólo está facilitando al lector los datos contextuales que se requieren para comprender el texto, también está haciendo evidente el carácter literario de su composición y de alguna manera jugando, si se nos permite el término, con la ausencia de contexto efectivo. ${ }^{12}$

\section{Tipos de FPO en la poesía helenística}

La ventaja del concepto de FPO frente a otros enfoques establecidos está en su capacidad de vincular una necesidad compositiva (la construcción de un contexto para la definición del género literario) con la posibilidad de trastocar, manipular y adaptar los recursos que se utilizan para satisfacerla. Un aspecto en donde esto se observa es la incorporación de rasgos de un género en poemas que se identifican claramente con otro: el hecho de que Argonáuticas se presente como un poema épico ejecutado en su contexto original le permite tomar como matriz genérica a la épica y al mismo tiempo añadir elementos de otros géneros que refuerzan el efecto ficcional y aumentan el potencial expresivo sin desdibujar la matriz fundamental. ${ }^{13}$ Por otro lado, los aspectos performativos incorporados al texto adquieren diferentes funciones narrativas: el 'comienzo hímnico' de Argonáuticas funciona como exordio y como proemio, ${ }^{14}$ en tanto que Apolo no sólo aparece como el dios que auspicia al poeta y su canto, sino que tiene un papel central en la trama como primera causa de la expedición por medio del oráculo que recibe Pelias (1.8) y como protector de la expedición (entre otros, en 1.411-414). ${ }^{15}$

Los epigramatistas y Apolonio nos presentan técnicas de FPO que recuperan y manipulan contextos performativos heredados de las épocas arcaica y clásica, evidenciando el proceso básico que el concepto propone, esto es, el paso del estudio de un contexto real a uno generado por los propios poemas. En efecto, tanto el epigrama como la performance épica son géneros establecidos y acaso estudiados por los alejandrinos: su recuperación y adaptación pueden ser vistos como un paso más allá del trabajo filológico con ellos. Sin embargo, el concepto puede ser aplicado con éxito en un ámbito completamente
12. Cfr. Bing; Bruss (2007:1-14) y Bettenworth (2007:73-83).
13. Lo que Harrison (2007) denomina 'enriquecimiento genérico'; nótese que este concepto no debe confundirse con el más tradicional de Kreuzung der Gattungen que pretende superar.

14. Tomamos esta distinción de Càssola (1975:xvii-xxi). La performance de poemas épicos se ejecutaba en una serie de rapsodias, cada una con un inicio y un final propios. El término 'proemio' corresponde a la primera de esa serie de rapsodias Puesto que esta primera rapsodia era generalmente un himno, esto es lo que - desde el trabajo de Wolf en el s. XVIII en adelante - se ha llamado 'himno en función proemial'. Por su parte, el término 'exordio' corresponde al inicio de cada una de las rapsodias de la serie (incluso de la primera).

15. Para un análisis más detenido de la FPO en Apolonio, cfr. Llanos (2017). 
diferente: el de la pastoral. La idea de que la noción de 'mímesis' no sirve para comprender el desarrollo de este género ya ha sido propuesta antes y se ha sugerido que es necesario entender la construcción del poema bucólico como la de un mundo ficticio (Payne, 2006; las propuestas fundamentales han sido resumidas por Hunt, 2009:1-3).

Pero, mientras que se ha visto lo que es original y propio de Teócrito en esta técnica, no parece haberse observado lo que comparte con sus contemporáneos: fabricar un mundo donde los pastores cantan y compiten en la composición de poemas es concebir para los textos una FPO. Más específicamente, es concebir una FPO que no se identifica con un contexto poético clásico, sino que construye para sí uno nuevo. La estrategia va un paso más allá de la que se ve en los epigramas que 'inventan' estatuas o tumbas; en lugar de limitarse a crear un contexto particular dentro de un tipo reconocido de contextos, Teócrito ha inventado un mundo en el que la poesía y la vida tienen sus propias reglas.

Esto permite entender por qué la bucólica es un género propiamente helenístico: en un espacio cultural en el que el contexto de performance está dado, uno ficticio no podría nunca fabricarse; sin embargo, esa fabricación está a un corto paso del momento en que el contexto de performance se vuelve una ficción que los poemas elaboran. Debe notarse, además, que la diferencia en la técnica de Teócrito se observa en un tipo especial de marcador que el poeta utiliza: mientras que la mayor parte de los textos conservados se presentan como poemas con un contexto específico sin ninguna aclaración, algunos Idilios conservados aparecen 'encapsulados' por un comentario o una introducción del autor, ${ }^{16}$ que media entre el receptor y el contexto ficticio de performance original. La mediación facilita el reconocimiento de un contexto de performance no-tradicional. Obsérvese el recurso en funcionamiento en Id. 6.1-4:

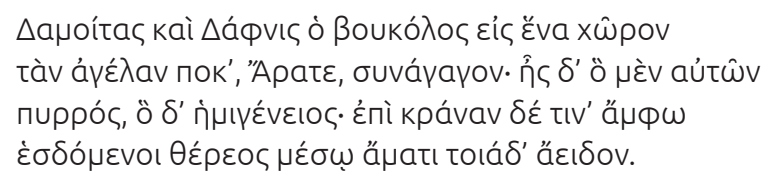

Dametas y Dafnis el vaquero hacia un mismo lugar condujeron una vez el rebaño, Arato; uno de ellos tenía el primer vello rubio, el otro ya medio bozo; junto a una fuente ambos, sentados en un mediodía de verano, cantaron estas cosas.

La introducción no es sólo un recurso heredado de la épica para contextualizar narrativamente al receptor: también ofrece los datos fundamentales para reconstruir el contexto de performance de lo que sigue. No hace diferencia si se escucha una recitación cortesana del poema o se lee en una biblioteca: el contexto en el que debe comprenderse el canto de Dametas y Dafnis es provisto por el propio poeta, de la misma manera que el epigrama literario indica al lector que debe pensarlo en, por ejemplo, una tumba.

La FPO de Teócrito es más compleja que la de Apolonio o los epigramatistas, puesto que no sólo genera un contexto de performance sino que se sale de la tradición para crear un nuevo tipo de contexto de performance. Exhibe, en ese sentido, una forma extrema de la técnica, en la que la creación del poeta trasciende los límites de lo heredado. Otra forma extrema se observa en la Alejandra de Licofrón, un poema épico escrito en trímetro yámbico y presentado en el modo típico de los 'relatos de mensajero' del drama (Fantuzzi; Hunter, 2004:437-441). 
En este caso, no hay creación de un nuevo contexto de performance, sino en cierto sentido el desarrollo de un fenómeno típicamente filológico (el extracto de pasajes) como forma poética independiente. El gesto se hace evidente desde el comienzo de la obra (vv. 1-4):

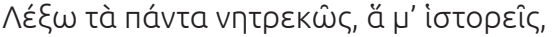

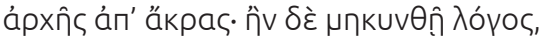

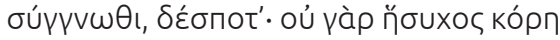

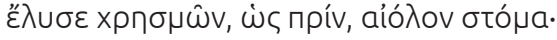

Diré todas las cosas con exactitud, por las que me preguntas, desde el mismo comienzo; y si se alarga el discurso, perdona, soberano: pues la doncella no gentilmente liberó, como antes, su veloz boca, profetizando.

La cita puede compararse con, por ejemplo, A. Th. 458 o Eur. IA. 1541, dos versos que están en el inicio de un relato de mensajero y que empiezan con

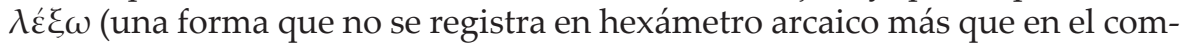
puesto $\kappa \alpha \tau \alpha \lambda \dot{\varepsilon} \xi \omega$, lo que distingue a la Alejandra de ese tipo de poesía desde la primera palabra). Nótese, por lo demás, el evidente esfuerzo por crear la ilusión de un diálogo a través de las segundas personas en los vv. 1 y 3 y el vocativo en el v. 3 (limitándonos solo a los versos citados).

No sólo la introducción (vv. 1-30) y el cierre del texto (vv. 1461-74) hacen inconfundible el marco trágico y llevan a pensar en un drama convertido en un monólogo, sino que el uso constante del trímetro yámbico garantiza que el poema no sea interpretado como una epopeya o como una profecía. Ahora bien, reconocer que Licofrón ha construido un contexto dramático para su relato épico es reconocer un tipo de FPO peculiar para un poeta con rasgos únicos. Es precisamente la posibilidad de crear un espacio teatral ficticio lo que permite desarrollar un 'relato de mensajero' imposible por su extensión y su complejidad. La performance dramática de la Alejandra se enriquece incorporando elementos de la épica y el lenguaje profético, pero el constante trímetro yámbico impide al receptor olvidar que está escuchando o leyendo una tragedia.

Una ventaja adicional del concepto que se presenta en este trabajo es que permite superar no sólo la oposición esquemática entre poemas 'miméticos' y 'no miméticos', sino desplazar la discusión de base que lo fundamenta, esto es, si un determinado texto o conjunto de textos fueron compuestos o no para ser recitados o cantados. Esto se observa claramente en el caso de Herondas. En este autor de mimos, la pregunta por si sus poemas fueron ejecutados y en qué contexto ha sido un problema crítico (en los dos sentidos de 'crítico') durante mucho tiempo. El concepto de FPO no lo resuelve, pero lo desplaza de manera definitiva. Dado que los textos construyen su propio contexto de performance, son absolutamente incapaces de darnos pistas sobre su contexto efectivo de performance. Pero esto no es porque, como observa Hunter (1993:3132), un rasgo que podría parecer performativo podría ser una mera imitación literaria, sino porque no es posible aproximarse a los rasgos performativos buscando una relación efectiva con su contexto real. ${ }^{17}$ FPO quiere decir que el texto construye un contexto de performance 'ficticio' independientemente de su contexto de performance real (si lo hubiere). ${ }^{18}$

En el mimo de Herondas la técnica es utilizada magistralmente, no sólo porque el metro, el esquema dialógico y el lenguaje sugieren un tipo específico de contexto teatral, sino porque el autor enriquece esta matriz con complejas
17. Piénsese en el caso de Teócrito: interpretar literalmente (o casi literalmente) los versos del Idilio 6 citados arriba implicaría que el autor de hecho espera que su poema sea cantado por campesinos en un campo junto a una fuente. Incluso si uno quisiera comprometerse con la idea de una tradición de poesía pastoril de la que Teócrito se nutre (cfr. sobre el tema Hunt, 2004:733), proponer que sus poemas estaban diseñados para ser interpretados por pastores sólo puede ser clasificado como ridículo. Lo que pretendemos señalar no es que la situación sea la misma en Herondas (de más está decir que una ejecución efectiva de los mimos es más que posible), sino que el hecho de que un texto construya su contexto no significa de ninguna manera que deba ser ejecutado en ese contexto.

18. El lector puede pensar que no tiene demasiado sentido sostener un contexto ficticio diferente del real: si un mimo es ejecutado, es una obra performativa en el sentido básico que vale para las épocas arcaica y clásica. Sin embargo, considérese la situación de una lectura de los mimos hecha por un solo recitador o dos en la corte ptolemaica o la biblioteca, sin ningún tipo de escenificación teatral: es claro que los poemas de Herondas no construyen para sí mismos un contexto como ese, que no por eso deja de ser un contexto de performance efectivo. 
alusiones y auto-referencias (cfr. Fernández, 2006, con sus referencias), algo que puede ejemplificarse con 4.32-34, un poema en el que dos mujeres poco instruidas visitan el templo de Asclepio y se admiran ante las obras de arte allí expuestas:

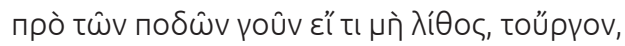

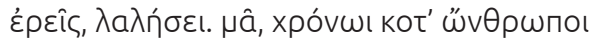

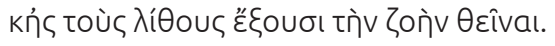

A los pies, por cierto, si no fuera piedra, la obra, dirías, va a hablar. Sí, con el tiempo los seres humanos también en las piedras podrán poner vida.

Fernández (2006:33-35) muestra que estas observaciones, junto con las que las rodean, funcionan simultáneamente en dos planos: por un lado, el escenario cómico de las mujeres rústicas admirándose por las obras de arte trabaja, por así decirlo, en el nivel de la burla a los personajes del mimo; por el otro, sin embargo, el episodio presenta (p. 35)

aunque deformados y exagerados con propósitos probablemente humorísticos, criterios de evaluación estándares de la estética helenística vigente, testimoniados en una plétora de epigramas que exaltan el verismo del arte de la época.

La coexistencia de estos niveles está habilitada por la construcción de un contexto de performance: la burla a las mujeres rústicas es lo que el espectador del mimo espera del género, mientras que la red de referencias culturales puede leerse como un guiño al receptor culto secundario.

El último caso que es necesario mencionar brevemente es el de los himnos de Calímaco, puesto que son quizás los que han dado lugar a las mayores y más aporéticas discusiones sobre el carácter mimético de la poesía. Dado que la cuestión será estudiada en detalle en un artículo en este mismo volumen, basta aquí con señalar que el concepto de FPO resuelve esta discusión de manera similar a la forma en que resuelve la discusión en el caso de Herondas, es decir, desplazándola fuera del análisis interno del texto. Pero en el caso de Calímaco la complejidad de la técnica es mucho mayor, porque en cada uno de sus himnos se observa una manipulación distinta y específica del contexto de performance y un enriquecimiento genérico de una gran sofisticación. El poeta no solo incorpora espacios y ocasiones tradicionales que el receptor puede identificar sin dificultad, sino que los manipula adaptándolos a las nuevas circunstancias culturales. Así, por ejemplo, en el Himno a Zeus no solo observamos un himno rapsódico tradicional, sino también la incorporación de una serie de marcadores de otros géneros literarios que enriquecen la técnica himnódica permitiendo la referencia a concepciones religiosas de la Alejandría ptolemaica (Abritta, 2014).

Si en este breve recorrido por una serie de autores la amplitud del concepto de FPO de alguna manera termina atentando contra su coherencia interna, debe recordarse que lo esencial de la propuesta está en la historia de la técnica. El cambio cultural en la época helenística que experimentan sobre todo los hombres cultos (que son los que escribieron la inmensa mayor parte de los poemas que nos han llegado) alienó a los textos de la tradición de su contexto de performance, un proceso que afectó profundamente su naturaleza y sus posibilidades de recepción. La reconstrucción de esos contextos a partir de fuentes 
indirectas, pero sobre todo a partir de los propios textos se convirtió en un modo de pensar la poesía. Al producir nuevos textos, los autores helenísticos aplicaron lo aprendido, incorporando los marcadores que la tradición les había legado para construir (no ya reconstruir) contextos de performance originales.

\section{Conclusiones}

Aunque se necesita un estudio específico para cada uno, algunas de las respuestas que los poetas dieron al problema de los cambios en los contextos de ejecución poética han sido exploradas en este trabajo. En Herondas, el metro y el carácter dialógico de los mimos crean un espacio teatral que el receptor reconoce inmediatamente. En Licofrón sucede algo similar, con la salvedad de que un recurso dramático (el 'relato de mensajero') es llevado al extremo; el uso del trímetro yámbico a lo largo de todo el poema, sin embargo, hace inconfundible el modo de performance original que el texto construye para sí. Teócrito, hemos notado, no crea un contexto de performance, sino que fabrica el mundo en el cual sus poemas son ejecutados; en él, la FPO alcanza un grado de desarrollo que llega casi al punto de quebrar al propio concepto a favor de una noción más amplia (y más contemporánea, quizás) de 'espacio ficcional'. En Argonáuticas, la FPO se genera con sutileza: la tradición rapsódica en la que Apolonio se apoya tiene pocos marcadores performativos, pero el poeta los incorpora y utiliza de maneras claras para construir y también para manipular un contexto fácilmente reconocible. Por último, en el epigrama literario helenístico la fabricación de los monumentos y objetos consagrados a través de su descripción detallada o a veces de su simple mención muestra la manera en la que los poetas fueron capaces de apropiarse de un género respetando un elemento esencial, es decir, el contexto de la inscripción, pero al mismo tiempo modificando por completo la manera en que ese elemento es utilizado.

En última instancia, las ventajas del concepto de FPO sobre la noción más tradicional de 'mímesis' pueden resumirse en tres proposiciones: primero, la creación de un contexto de performance a través de marcadores incorporados en los propios textos es coherente con lo que sabemos de la historia de la poesía griega y del contexto cultural helenístico; segundo, la idea de una FPO independiente del problema de la ejecución real, si no resuelve, sí desplaza el problema de la performance efectiva fuera del ámbito estricto de la filología al de las ciencias de la cultura en sentido amplio; y, finalmente, la construcción de un contexto de performance en los propios textos elimina la contradicción entre 'mímesis' y enriquecimiento genérico y alusiones cultas: la posibilidad de manipular los marcadores genéricos no sólo es compatible con la noción de FPO, es esencial a ella. 


\section{Q Bibliografía}

" Abritta, A. (2014). "Hacia una historia coral de la himnodia griega: experimentos literarios y memoria cultu(r)al en los Himnos de Calímaco", Anales de Filología Clásica $27,5-18$

» Bettenworth, A. (2007). "The Mutual Influence of Inscribed and Literary". En: Bing, P.; Bruss, J. S. (2007) (eds.). Brill's Companion to Hellenistic Epigram, Leiden: Brill, 69-94.

" Bing, P.; Bruss, J. S. (2007). "Introduction to the Study of Hellenistic Epigram". En: Bing, P.; Bruss, J. S. (2007) (eds.). Brill's Companion to Hellenistic Epigram, Leiden: Brill, 1-28.

» Càssola. F. (1997) Inni Omerici. Milano: Fondazione Lorenzo Valla. 1º ed. 1975.

»Comotti, G. (1989). "Melodia e accento di parola nelle testimonianze degli antichi e nei testi con notazione musicale", QUCC 32, 91-108.

» Fantuzzi, M.; Hunter, R. (2004). Tradition and Innovation in Hellenistic Poetry, Cambridge: Cambridge University Press.

» Fernández, C. N. (2006). "Herondas por Herondas: autoficción en el mimo helenístico", AC75, 23-39.

» Ford, A. (1988). "The Classical Definition of PAYOAIA", CPh 83, 300-307.

"Gow, A. S. F.; Page, D. (1965). The Greek Anthology. Hellenistic Epigrams, vol. 1: Introduction, Text, and Indexes of Sources and Epigrammatist. Cambridge: Cambridge University Press.

" Harrison, S. J. (2007). Generic Enrichment in Vergil \& Horace. Oxford: Oxford University Press.

" Hunt, J. M. (2009). Fiction and Mimesis in the Idylls of Theocritus, PhD Dissertation, Brown University, Providence.

» Hunter, R. (1993). "The Presentation of Herodas' Mimiamboi", Antichthon 27, 31-44.

» Huron, D. (2006). Sweet Anticipation. Music and the Psychology of Expectation. Cambridge: MIT Press.

"Llanos, P. M. (2017). "Ficción de performance original en el exordio de Argonáuticas de Apolonio de Rodas", Synthesis 24, e013.

» Payne, M. (2006). Theocritus and the Invention of Fiction. Cambridge: Cambridge University Press.

》 Rossi, L. E. (1971). "I generi letterari e le loro leggi scritte e non scritte nelle letterature classiche", BICS 18, 69-94.

» Rotstein, A. (2012). "Mousikoi Agones and the Conceptualization of Genre in Ancient Greece", Clant 31, 92-127. 